\title{
A mexicana Myriam Moscona e a renovação do judeu espanhol: ladino e português em proximidade
}

\section{Myriam Moscona and the renewal of Judeo-Spanish (Ladino)}

Wedja Paraizo* e Moacir Amâncio**

Resumo: O judeu espanhol, ou ladino, idioma dos judeus sefarditas fixados no antigo Império Otomano, após a expulsão dos judeus da Espanha. O idioma, hoje popularizado pela Internet, que confere visibilidade à atuação de seus falantes e pesquisadores, com realização de eventos que contam com a presença de especialistas e herdeiros da cultura judaica provenientes da Ibéria. Ao mesmo tempo, surgem textos que retomam a tradição do ladino em prosa e verso. A poeta mexicana Myriam Moscona é uma das autoras que se destacam nesse movimento de memória e renovação cultural verificado em diversos países.

Palavras-chave: Sefarditas. Castelhano. Poesia. Tradução. Ladino.

\begin{abstract}
The Judeu Espanhol or ladino, language of the Sephardic Jews settled in the old Ottoman Empire, after the expulsion from Spain (1492). The language, popularized today by the Internet, givers visibility to the actions of its speakers, with events held with the presence of experts and heirs of Jewish culture from Iberia. Até the same time, texts emerge that take up the tradition of the Ladino in prose and verse. The Mexican poetess Myriam Moscona is one of the author who stand out in this movement of memory and cultural renewal verified in several countries.
\end{abstract}

Keywords: Sephardic. Castilian. Poetry. Translation. Ladino.

1. Myriam e sua linguagem.

Escritora, jornalista, tradutora e também poeta, Myriam Moscona pertence a uma família de judeus búlgaros sefarditas. Seus pais, após deixarem a região da Bulgária em 1948, vivem

\footnotetext{
* Wedja Paraizo, graduanda em Letras Português-Hebraico pela Universidade de São Paulo, é formada em Administração e Logística pelo Centro Paula Souza. Inaugurou sua publicação poética na coletânea Além da Terra, Além do Céu, da Editora Portuguesa Chiado Books, 2019.

** Professor titular da Universidade de São Paulo.

Email: <moaman@globo.com>.
} 
por três anos em Israel e em seguida partem para o México, lugar onde se estabelecem e onde nasce Myriam no ano de 1955.

A partir de então, desde a infância da escritora, a questão linguística surge como um desafio de adaptação em outro país, não apenas para ela, mas principalmente para seus familiares, todos eles falantes do búlgaro e do judeu espanhol, ou ladino, uma língua que era um amálgama de palavras em castelhano, turco, francês, italiano, português, grego, búlgaro, entre outros idiomas presentes na Turquia e regiões balcânicas habitadas pelos seus falantes. No México, a família aprende o castelhano, língua que a escritora não apenas dominou na fala e na escrita: é nela que constrói sua própria literatura e mais do que isso, é a partir daí que Moscona estreita o contato com o judeu espanhol, ou ladino.

Identificar raízes, reavivar a herança da língua castelhana, bem como a da própria literatura, foi o que a poeta fez ao incorporar o judeu espanhol em sua obra, valendo-se das marcas da contemporaneidade, firmando um estilo novo que se distancia do padrão lírico anteriormente associado à expressão literária na língua, como já foi observado a respeito de sua obra. Observa-se com isso o efeito de modernidade que a escritora consegue imprimir aos poemas. O fenômeno pode ser notado na obra de outros escritores e escritoras sefarditas e mesmo na experiência em judeu espanhol do poeta argentino Juan Gelman, de origem asquenazita, em Dibaxu, obra traduzida para o português pelo poeta Andytias Soares de Moura (dibaxu/debaixo, Edium/Secretaria da Cultura do Estado do Ceará/Universidade Federal do Ceará, 2009).

A tradução dos poemas de Myriam para a língua portuguesa vem carregada de significados. Além de inaugural, reflete-se o encontro das origens desses dois idiomas. Da proximidade entre o judeu espanhol e o português resultam semelhanças facilmente identificáveis pelo leitor que terá, nesse momento, a oportunidade de conhecer as diversas camadas semânticas num exercício de leitura que amplia o alcance da poesia de Myriam Moscona também no âmbito latino-americano.

2. Sobre o poema "A anunciação"

O poema A anunciação, de Miryam Moscona, oscila entre a narrativa e o diálogo do eu lírico. Essa anunciação, por vezes enigmática, que se desenvolve em prosa poética. Num jogo dramático entre desejo e realização-frustração, numa trajetória feita à pé quebrado. 


\section{A ANUNCIAÇÃO}

Observo-a desde a água: vem ela oferecer-se na fornicação do nome. Desenho sua sombra, lhe falo bem na treva do ouvido. Amarga: Não te toco. Talvez o olho somente deva ver-te e voltar.

$* * *$

Quisera conhecer a exultação de sua carne. Por ela cobri meus quadris com sedas orientais, fortaleci meu corpo, envolvi minha vida em torno de sua graça.

Por ela aprendi a rezar.

Quisera seus olhos a depravar-me em seus cuidados, sacrificar-lhe carneiros. Agradou-se dos meus atos: bebeu de minha mão, escondeu-se atrás das minhas amoreiras, dormiu debaixo do castanheiro de minha casa e numa noite pousou em meus rascunhos.

Traçou sinais, mostrou-me o caminho que conduz à muralha e ao desenhar no papel uma cidade ela se perdeu nas linhas como um cão imaginário.

$* * *$

Eu a cobri com unções, dei-lhe leite de cabra, aqueci para ela poções no caldeirão. Coloquei papoulas em sua língua, injetei em suas pupilas minhas visões, pressionei contra sua mão uma semente. Aqui está a utópica árvore, eu lhe disse, mas ela se recusou a falar.

$* * *$

Quando se anda a pé quebrado e se cavalga em linha reta até a direção ao caminho onde o jambo oferece seu verdor, é possível dominar a orla. A partir desse ponto, a descida brilha e se expande. Em todos os sentidos, o cume aponta para o vazio. 


\section{LA ANUNCIACIÓN (original castelhano)}

La miro desde el agua: viene a ofrecerse en la fornicación del nombre. Dibujo su sombra, le hablo a lo negro del oído. Amarga: No te toco. Acaso el ojo sólo deba verte y regresar.

$* * *$

Quise conocer la exultación de su carne. Por ella cubrí mis caderas con sedas de oriente, fortalecí mi cuerpo, rodé mi vida en torno de su gracia.

Por ella aprendí a rezar.

Quise sus ojos, depravarme en sus cuidados, sacrificarle carneros. Y le agradaron mis costumbres: bebió de mi mano, se ocultó tras mis zarzales, durmió bajo el castaño de mi casa y una noche se posó en mi borrador.

Trazó unos signos, me mostró el camino que conduce a la muralla y al dibujar sobre el papel una ciudad se perdió en las líneas como un perro imaginario.

$* * *$

La cubrí de unciones, le di leche de cabra, le entibié pócimas en el caldero. Puse amapolas en su lengua, inyecté en sus pupilas mis visiones, apreté contra su mano una semilla. Aquí está la utopía del árbol, le dije, pero ella se negó a hablar.

$* * *$

Cuando se anda a pie quebrado y se encabalga en línea recta hacia el sendero donde el yambo ofrece su verdor, se llega a dominar el borde. Desde ese punto el descenso brilla y se dilata. En todos los sentidos la cumbre apunta hacia el vacío. 
3. Sobre o poema "De Ansina / De Ensonhos"

Escrito em judeu espanhol, o seguinte poema enquadra nos seus versos um sonho de conquista que é sufocado pela submissão a uma realidade que não condiz com o que deseja o eu lírico. A primeira estrofe vem carregada de uma abnegação que mais tarde é corroborada e também questionada na segunda estrofe, onde o eu lírico busca uma espécie de poder que já lhe parece medido, encomendado. A ideia de submissão consciente em vez de levar à acomodação, provoca um desejo de retomada, quando o controle e a força são simbolizados pela visão de uma coroa inalcançável.

\section{DE ANSINA}

\section{DE ENSONHOS}

quis

fazer de mim

uma

leoa

mas eu

me joguei

a seus sapatos

e passei

a vida

empinando o lombo

a acalentar seus pés

a sonhar

com uma coroa

que bem me caia na cabeça.

\section{DE ANSINA}

DE EFSUENYOS (original judeu espanhol/ladino) 
kizo

fazer de mi

una

leona

ama yo

me echí

a sus sapatos

i pasí

la vida

alevantando el lomo

kayentando sus piezes

i sonyando

kon una korona

para meterme en la kavesa

\section{Bibliografia}

VANGUARDIA, La. MOSCONA, Myriam. "Los hombres olvidamos, pero las lenguas, no". Artículos, Centro Cultural Sefarad, 2020. Disponível em: < https://esefarad.com/?p=57289> Acesso em: 23/08/2021.

MOSCONA, Myriam - El Ladino: Herencia Y Descubrimiento. Youtube. Centro Cultural Sefarad, 2020. Disponível em: <https://www.youtube.com/watch?v=Fu-6vJhwoBU>. Acesso em: $11 / 08 / 2021$.

MOSCONA, Myriam - Selección De La Autora. Nota Introductória de Margo Glantz. Universidad Nacional Autónoma de México Ciudad Universitaria . México, $1^{\text {a }}$ Ed. 2013. Disponível em: <http://www.materialdelectura.unam.mx/images/stories/pdf5/myriammoscona-208.pdf>. Acesso em: 01/06/ 2021. 